\title{
Injection of thyrotropin releasing hormone into the locus coeruleus increases blood pressure
}

\author{
I. PaakKari*, A.-L. Siren*, M.-L. Nurminen and M. Svartström-Fraser $\dagger$ \\ Department of Pharmacology and Toxicology, University of Helsinki, Siltavuorenpenger 10, SF-00170 Helsinki, \\ Finland
}

KEY WORDS: TRH, blood pressure, locus coeruleus.

Thyrotropin releasing hormone $(T R H), 10$ pmol $\mathrm{kg}^{-1}$ injected in the region of locus coeruleus, caused a rapid (within I min) rise of mean arterial pressure in the urethane-anaesthetized rat. No clear-cut effects in heart rate or ventilation were observed. When TRH was injected into the lateral ventricle, a dose more than 10-fold higher was required to achieve a comparable rise in arterial pressure. It is concluded that TRH may have a physiological role in central cardiovascular regulation.

\section{Introduction}

Intracerebroventricularly (i.c.v.) administered thyrotropin releasing hormone (TRH) increases blood pressure and heart rate in various animal species ${ }^{[1-3]}$. Also, when given intravenously (i.v.) to man for testing hypophyseal function, TRH increases blood pressure $^{[4]}$. We have recently shown, in the rat, that TRH injected into the fourth cerebral ventricle induced a more rapid hypertensive effect than when injected into the lateral ventricle ${ }^{[5]}$. Moreover, hypertension persisted when TRH was injected into the fourth ventricle if its access to the rest of the cerebral cavities was hindered by blockade of the cerebral aqueduct. Therefore, the brain stem appeared to be the main site for the hypertensive action of TRH.

The present study provides further evidence of an extrahypothalamic site for the cardiovascular action of TRH by comparing effects of its administration i.c.v. and locally in the region of the locus coeruleus.

\section{Methods}

Male Wister rats (250-370 g) were anaesthetized with urethane ( $1.5 \mathrm{~g} \mathrm{~kg}^{-1}$ intraperitoneally) and the trachea was cannulated for recording of spontaneous ventilation. The left femoral artery was cannulated

\footnotetext{
* Present Address: Uniformed Services University of the Health Sciences, Dept of Neurology, Neurobiology Research Division, 4301 Jones Bridge Road, Bethesda, Maryland 20814, U.S.A.

† Present address: Orion Pharmaceutical Company, Tuotekehitys, PL 65, SF-02101 Espoo, Finland.

Address Correspondence to Ilari Pakkari.
}

for recording of blood pressure. Expiratory air flow was recorded by means of a hot wire flow meter placed at the opening of the tracheal tube. Colonic temperature was maintained at $37 \pm 0 \cdot 3^{\circ} \mathrm{C}$ by means of a heating pad controlled by a thermistor probe.

The rats were held in a stereotaxic instrument for i.c.v. or intracerebral (i.c.) injections. The technique for cannulation of the lateral cerebral ventricle, and details of the computerized recording system, have been described previously ${ }^{[6,7]}$. For i.c. injections, a stainless steel guide cannula was inserted bilaterally at the following coordinates in reference to the bregma: $A P=-6.2, L=1.0, V=2.0 \mathrm{~mm}$. To reach the region of locus coeruleus, a $30 \mathrm{G}$ stainless steel tubing was inserted via the guide cannula. The coordinates were defined according to the atlas of Pellegrino et $a l^{[8]}$ In the vertical plane, depths of 6.0 or $7.0 \mathrm{~mm}$ from the skull surface proved to correspond to the level of the locus coeruleus. Details of post-mortem verification of injection sites are shown in Fig. 1.

The injections were given within $15 \mathrm{~s}$ in volumes of $1 \mu 1$ (i.c.) or $10 \mu \mathrm{l}$ (i.c.v.). At the end of the experiment, the tip of the cannula was marked with methylene blue for verification of the injection site. Each brain was then removed and stored in formalin and cut after $48 \mathrm{~h}$ in serial slices $(50 \mu \mathrm{m})$ for microscopic examination.

TRH hydrochloride (Sigma Chemical Co.) was dissolved in saline $(0.9 \% \mathrm{NaCl} w / v)$.

Two-way analysis of variance for repeated measures was used for statistical assessment. The difference between two groups was denoted as significant 

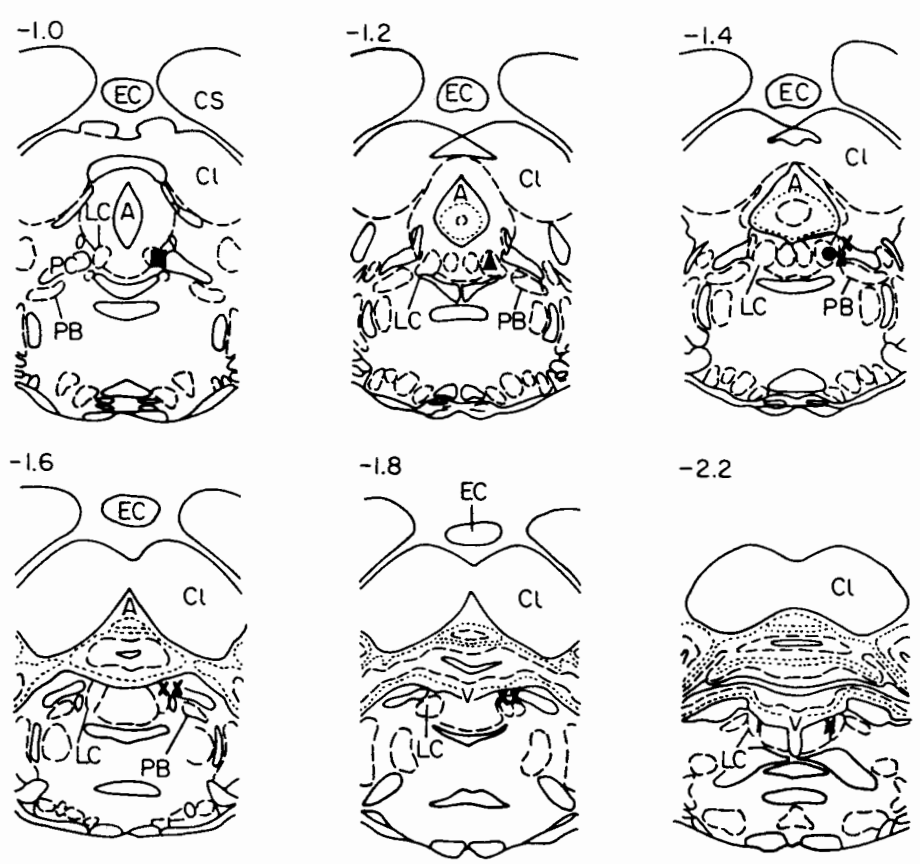

Figure I Microscopically verified injection sites are drawn on a series of frontal sections of the brain stem. The number of verified injection sites is shown on the right half of the brain stem as follows: $x=1, \boldsymbol{D}=3, \bullet=4$, $\Delta=7$. For the sake of clarity, comparible injection sites on the left side are not shown. Abbreviations: $\mathrm{A}=$ cerebral aqueduct, $\mathrm{CI}=$ colliculus inferior, $\mathrm{CS}=$ colliculus superior, $\mathrm{EC}=$ epiphysis cerebri, $\mathrm{LC}=$ locus coeruleus, $\mathrm{PC}=$ pedunculus cerebellaris superior, $\mathrm{PB}=$ medial parabrachial nucleus, $\mathrm{V}=$ ventricle. The figure at the left corner of each section shows the interaural coordinate.

at the level of $\mathrm{P}<0.05$ (Tukey's test). Calculations were carried out by a VAX-8600 computer using SAS statistical software. The results are expressed as means $\pm \mathrm{SE}$.

\section{Results}

ADMINISTRATION OF TRH IN THE REGION OF THE LOCUS COERULEUS

TRH, 10 pmol kg-1 i.c., increased mean arterial pressure (MAP) by $24 \mathrm{~mm} \mathrm{Hg}$ within $1 \mathrm{~min}$, whereas the effect of $1 \mathrm{pmol} \mathrm{kg}^{-1}$ was not significantly different from the saline control group [Fig. 2(a)]. Compared with the saline control, neither of the treatment doses of TRH significantly affected heart rate [Fig. 2(b)] or ventilation rate [Fig. 2(c)].

Ventilation tidal volume was changed less than $10 \%$ during the 10-min follow-up after injection.
These changes were not statistically significant. Baseline values for tidal volumes (in $\mathrm{ml}$ ) were as follows: 1 pmol kg-1, $1 \pm 0 \cdot 1(N=8) ; 10 \mathrm{pmol} \mathrm{kg}^{-1}$ $1.2 \pm 0.2(\mathrm{~N}=7)$; and saline, $0.93 \pm 0.1(N=6)$.

ADMINISTRATION OF TRH INTO THE LATERAL VENTRICLE TRH, $100 \mathrm{pmol} \mathrm{kg}^{-1}$ i.c.v., increased MAP maximally by $14 \mathrm{mmHg}$ within $5 \mathrm{~min}$ of the injection [Fig. 3(a)]. Doses of 1 or $10 \mathrm{pmol} \mathrm{kg}^{-1}$ failed to alter MAP significantly.

Doses of 10 and 100 pmol kg-1 of TRH i.c.v. increased heart rate to the same amount. The peak effects (about $25 \mathrm{~min}^{-1}$ for both treatments) were reached within $5 \mathrm{~min}$ [Fig. 3(b)]. The effect of $1 \mathrm{pmol}$ $\mathrm{kg}^{-1}$ did not significantly differ from that of the salinetreated group.

TRH $100 \mathrm{pmol} \mathrm{kg}^{-1}$ i.c.v. increased ventilation rate maximally by 15 breaths $\mathrm{min}^{-1}$ within $3 \mathrm{~min}$ [Fig. 3(c)]. The two lower doses of TRH caused no 

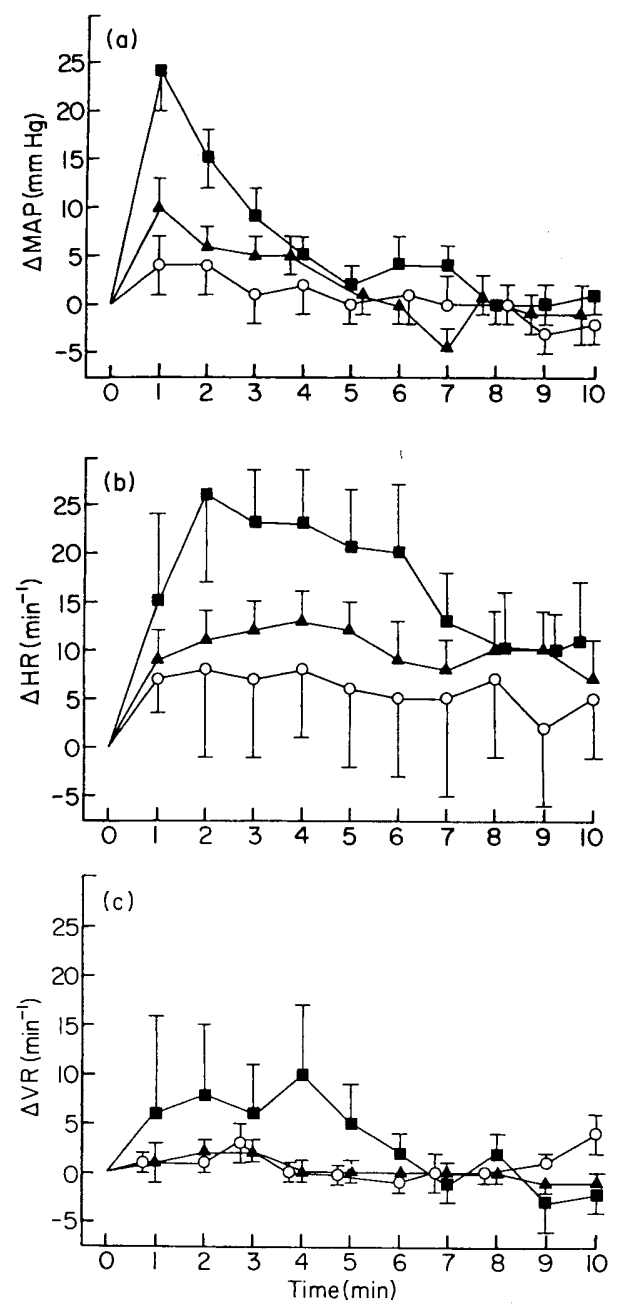

Figure 2 (a) Effects of TRH (given in two doses), and the saline control, injected into the region of locus coeruleus on mean arterial pressure (MAP). The symbols are denoted as follows (initial values in $\mathrm{mmHg}$ are shown in parenthesis): $\boldsymbol{\Lambda}=1 \mathrm{pmol} \mathrm{kg} \mathrm{kg}^{-1}(53 \pm 2, N=8) ; \boldsymbol{\square}=10 \mathrm{pmol} \mathrm{kg}^{-1}$ $(66 \pm 3, N=7) ; O=$ saline $(56 \pm 6, N=6)$. The differences between the TRH $10 \mathrm{pmol} \mathrm{kg}^{-1}$ group and the saline control were significant at 1-2 min. (b) Effects of 1 or 10 pmol kg-1 of TRH injected in the region of locus coeruleus on heart rate (HR). The symbols are the same as in (a). Initial values for $\mathrm{HR}$ in beats/min were: $1 \mathrm{pmol} \mathrm{\textrm {kg } ^ { - 1 }}$ $(440 \pm 5), N=8) .10 \mathrm{pmol} \mathrm{kg}^{-1}(420 \pm 15, N=7)$, saline $(417 \pm 16, N=6)$. The differences between the groups were not significant. (c) Effects of 1 or $10 \mathrm{pmol} \mathrm{kg}^{-1}$ of TRH injected into the region of locus coeruleus on ventilation rate (VR). The symbols are the same as in (a) Initial values for VR in breaths/min were: $1 \mathrm{pmol} \mathrm{kg}^{-1}(101 \pm 3, N=8)$. $10 \mathrm{pmol} \mathrm{kg}^{-1}(112 \pm 7, N=7)$, saline $(102 \pm 5, N=6)$. The differences between the groups were not significant.
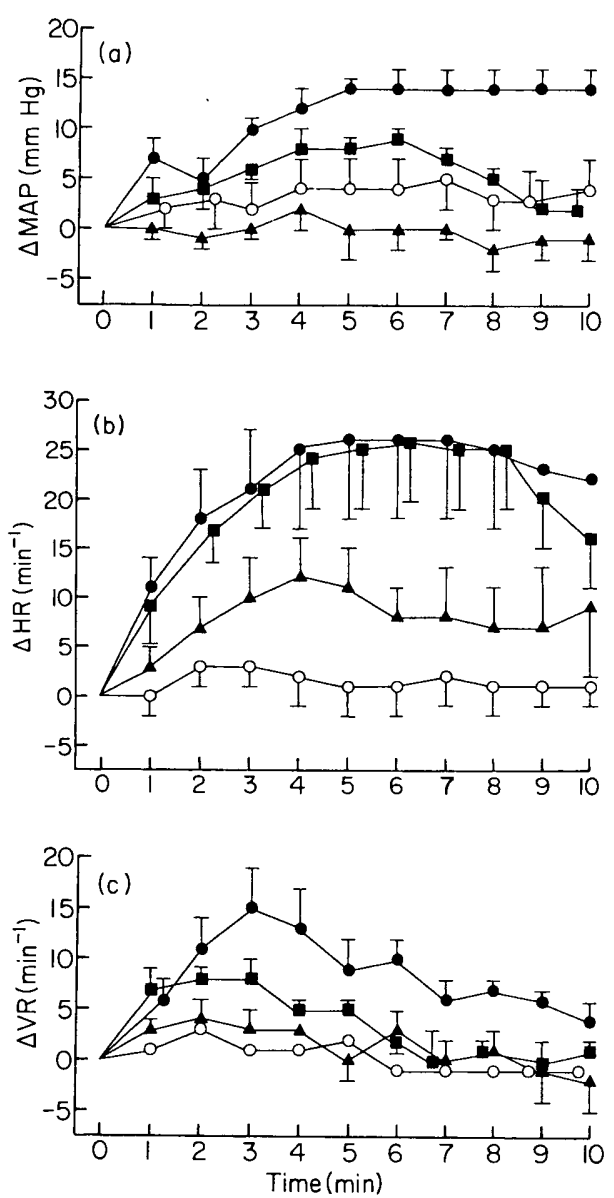

Figure 3 (a) Effects of 1,10 or $100 \mathrm{pmol} \mathrm{kg}^{-1} \mathrm{TRH}$ injected into the lateral cerebral ventricle on mean arterial pressure (MAP). The symbols are denoted as follows (initial values in $\mathrm{mmHg}$ are shown in parentheses: $\boldsymbol{\Lambda}=1 \mathrm{pmol} \mathrm{kg}$ $(75 \pm 6, N=8) ; \boldsymbol{\square}=10 \mathrm{pmol}^{\mathrm{kg}}{ }^{-1}(74 \pm 5, N=8) ; \boldsymbol{\bullet}=$ $100 \mathrm{pmol} \mathrm{kg}^{-1}(73 \pm 5, N=8), O=$ saline $(89 \pm 4, N=7)$. The effect of $100 \mathrm{pmol} \mathrm{kg}^{-1}$ of TRH differed significantly from that of the saline group at 3 and 5-8 min. (b) Effects of 1,10 or $100 \mathrm{pmol} \mathrm{kg}^{-1}$ of TRH injected into the lateral cerebral ventricle on heart rate (HR). The symbols are the same as in (a). Initial values in beats/min were: $1 \mathrm{pmol} \mathrm{kg-1}$ $(434 \pm 9, \mathrm{n}=8), 10 \mathrm{pmol} \mathrm{kg}^{-1}(442 \pm 9, N=8), 100 \mathrm{pmol}$ $\mathrm{kg}^{-1}(455 \pm 9, N=8)$, saline ( $\left.454 \pm 9, N=7\right)$. The effects of 10 and 100 pmol kg-1 of TRH differed significantly from those of the saline group at 2-8 min. (c) Effects of 1,10 or $100 \mathrm{pmol} \mathrm{kg}^{-1}$ of TRH injected into the lateral cerebral ventricle on ventilation rate (VR). The symbols are the same as in panel (a). Initial values in breaths $/$ min were: $1 \mathrm{pmol}$ $\mathrm{kg}^{-1}(113 \pm 3, N=8), 10 \mathrm{pmol} \mathrm{kg}^{-1}(110 \pm 3, N=8)$, $\left.100 \mathrm{pmol} \mathrm{kg}^{-1}(108 \pm 2, N=8), N=8\right)$, saline (103 \pm 5 , $N=7$ ). The effects of $100 \mathrm{pmol} \mathrm{kg}{ }^{-1}$ of TRH differed significantly from those of the saline group at 3-8 min. 
significant change. Changes in ventilation tidal volume at all doses of TRH were less than $11 \%$ and did not statistically differ from the changes in the control group. Initial values for the ventilation tidal

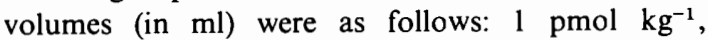
$1.2 \pm 0.2(N=8) ; 10 \mathrm{pmol} \mathrm{kg}^{-1} 1 \cdot 1 \pm 0.2(N=8)$; $100 \mathrm{pmol} \mathrm{kg} \mathrm{kg}^{-1} 1 \cdot 1 \pm 0.3(N=8) ;$ and saline, $1 \cdot 1 \pm 0.1(N=7)$.

\section{Discussion}

We have previously suggested that at least a part of the hypertensive effect of TRH is mediated via the brain stem ${ }^{[5]}$. Two pieces of evidence are available. Firstly, TRH induced a more rapid hypertensive response when injected into the fourth ventricle compared with injection into the lateral ventricle. Secondly, blocking the cerebral aqueduct did not attenuate the hypertensive action of TRH injected into the fourth ventricle, but abolished that after injection into the lateral vetricle, indicating that brain areas rostral to the block were not essential for the pressor effects of TRH.

The present findings show that an almost instantaneous hypertensive response $(1 \mathrm{~min})$ is obtained when TRH is injected into the region of the locus coeruleus compared to the much slower pressor effect after injection into the lateral ventricle and the intermediate response $(3 \mathrm{~min})$ after fourth ventricle administration seen in a previous study ${ }^{[s]}$. However, the effects of TRH were equal for both of these cerebroventricular routes of administration probably due to extensive mixing of the cerebrospinal fluid ${ }^{[9]}$. The present results also indicate that TRH doses more than ten times larger were needed i.c.v. than in the area of locus coeruleus to obtain similar increases in arterial pressure.

Diz and Jacobowitz ${ }^{[10]}$. reported slight increases of blood pressure after injection of TRH into the preoptic suprachiasmatic and medial preoptic nuclei at the dose of $1.4 \mathrm{pmol}$. However, the latent period between injection and peak effect was four times longer than in the present study, suggesting that the injection site was some distance from the locus of action. Likewise, the considerable latency of effect (10 min), despite a larger dose (nanomoles) injected into the medial preoptic nucleus ${ }^{[1]}$ suggests that this site is not involved in the hypertensive effect of TRH.

Administration of TRH into the region of the locus coeruleus failed to elicit any clear-cut tachycardia or stimulation of ventilation. Two previous studies also suggested that the site of TRH-induced tachycardia is not identical to that mediating hypertension ${ }^{[5.12]}$.

The exact location of centres mediating the hypertensive action of TRH in the rostral brain stem remains to be defined. It is likely that more than one nucleus is involved. That the sites of action reside in the immediate vicinity of the locus coerulus is suggested by the small dose of TRH required to elicit a clear increase in blood pressure, and the short interval between injection and the pressor response. In addition to the locus coeruleus ${ }^{[13]}$, the nucleus parabrachialis may also be involved, because of its known regulatory role ${ }^{[14]}$. Furthermore, both of the aforementioned sites have a high content of immunoreactive $\mathrm{TRH}^{[15]}$.

The observations that most TRH is found outside the hypothalmus, that its binding sites are widely distributed throughout the central nervous system, and that it is present in nerve terminals, suggest a role for TRH as a neurotransmitter ${ }^{[16]}$. The present findings, together with the biochemical and neuroanatomical data, suggest that TRH may have a physiological role in the regulation of the cardiovascular system.

This study was supported by the Finnish Academy and in part by the Orion Pharmaceutical Company. The skilful technical assistance of Mrs Helena Ekholm and Miss Beate Busch is gratefully acknowledged.

\section{References}

[1] Beale JS, White RP, Huang S-P. EEG and blood pressure effects of TRH in rabbits. Neuropharmacology 1977; 16: 499-506.

[2] Eriksson L, Gordin A. Cardiovascular and behavioral changes after i.c.v. infusion of TRH in the conscious goat. Pharmacol Biochem Behav 1981; 14: 901-5.

[3] Koivusalo F. Paakkari I, Leppäluoto J. Karppanen H. The effect of centrally administered TRH on blood pressure, heart rate and ventilation in rat. Acta Physiol Scand 1979; 106: 83-6.

[4] Borowski GD. Garofano CD. Rose LI, Levy RA. Blood pressure response to thyrotropin-releasing hormone in euthyroid subjects. J Clin Endocrinol Metab 1984; 58: 197-200.

[5] Paakkari I, Nurminen M-L, Siren A-L. Cardioventilator effects of TRH in anaesthetized rats: Role of the brain stem. European J. Pharmacol 1986; 122: 131-134.

[6] Paakkari I. A simple method for verification of a successful cannulation of the rat cerebral ventricles. Experentia 1980; 36: 887. 
[7] Paakkari I. Computerized recording of ventilation, cardiovascular parameters and body temperatures in anaesthetized rats. J. Pharmacol Methods 1981; 6: 97107.

[8] Pellegrino LJ, Pellegrino AS, Cushman AJ. A stereotaxic atlas of the rat brain. New York: Plenum Press, 1979.

[9] Hamperl H, Heller H. Die ausbreitung intrazisternal injizierte Stoffe im Liquorraum. Arch Exp Pathol Pharmakol 1933; 173: 283-90.

[10] Diz EI, Jacobowitz DM. Cardiovascular effects produced by injections of thyrotropin-releasing hormone in specific preoptic and hypothalamic nuclei in the rat. Peptide 1984; 5: 801-8.

[11] Feuerstein G. Hassen AH, Faden AI. TRH: Cardiovascular and sympathetic modulation in brain nuclei of the rat. Peptides 1983; 4: 617-20.
[12] Siren A-L, Paakkari I. Cardiovascular effects of TRH i.c.v. in conscious rats. Clin Exp Theory Pract 1984; A6(1011): 2073-7.

[13] Karppanen H. Paakkari I. Central catecholamine, 5hydroxytryptamine and histamine mechanisms in the regulation of circulation. In: Sleight $P$, Jones JV. Scientific foundations in cardiology. London: William Heinemann Medical Books Ltd, 1983; 50-6.

[14] Talman WT. Cardiovascular regulation and lesions of the central nervous system. Ann Neurol 1985; 18: $1-12$.

[15] Eskay RL, Long RT, Palkovits M. Localization of immunoreactive thyrotropin releasing hormone in the lower brain stem of the rat. Brain Res 1983; 277: 159-62.

[16] Jackson IMD. Thyrotropin-releasing hormone. N Eng] J. Med 1982; 306: 145-55. 